Research Article

\title{
MAJOR INSECT PESTS AND PESTICIDE USE PRACTICES AMONG TOMATO GROWERS IN KATHMANDU AND BHAKTAPUR DISTRICTS
}

\author{
K. Gauli ${ }^{*}$, L.P. Sah ${ }^{2 *}$, J.B. Shrestha ${ }^{1}$, B.P. Rajbhandari ${ }^{1}$ and A.R. Ghimire ${ }^{3}$
}

\begin{abstract}
The study was conducted at three municipalities of each Kathmandu and Bhaktapur districts to find out major pests and the practices of pesticide use to manage these pests from June to September 2019. Ninety respondents in total were interviewed, 15 from each municipality of Kathmandu and Bhaktapur districts using a simple random sampling method and based on structural questionnaire. The study revealed that among major pests of tomatoes, the South American tomato leafminer and whitefly were found to be problematic insect pests causing high economic loss. Around $26 \%$ of farmers were found practicing using only chemicals. Majority (55.5\%) of farmers were found practicing spraying pesticide at any time of the day. Around $42 \%$ of the farmers were found to have been applying pesticides before insect pest emergence. Farmers were ignorant of the frequency of pesticide use and most of the farmers were practicing spraying pesticide haphazardly than the recommended dose. $70 \%$ of farmers were dependent on agrovets for application of the dose of pesticides. About $11 \%$ were ignorant on the safety measures and did not use to any personal protective equipment while spraying pesticides. Regarding the disposal of pesticide, $46 \%$ farmers were practicing burying unused/expired pesticide. The study showed that nearly half of the respondents $(41.11 \%)$ were totally unaware of the information on the label and instruction given about pesticides. It was observed that most farmers were not acquainted with the right time, method, dose and safety measures of pesticide application.
\end{abstract}

Key words: Application, disposal, frequency, pesticides, safety.

\section{INTRODUCTION}

Tomato (Solanum lycopersicon) is one of the most important crops which is used both as a fresh vegetable and variety of processed products such as ketchup, sauce, juice, pasta sauce,

${ }^{1}$ Himalayan College of Agricultural Sciences and Technology (HICAST), Kirtipur, PO Box: 25535, Kathmandu, Nepal

2 Senior Technical Specialist, International Development Enterprises (iDE Nepal). PO Box: 2674, Kathmandu, Nepal

${ }^{3}$ Intern Student, Agriculture and Forestry University (AFU), Rampur, PO Box: 13712, Chitwan, Nepal

* Email for correspondence: karu.gauli@gmail.com; lpsah@ideglobal.org 
tomato-based powders, curries, sun-dried tomatoes and ready-to-eat products. It is native to Western South America. It has wider adaptability thus it is cultivated under various agroclimatic conditions of temperate, tropics and sub-tropics of the world. In Nepal, the area covered by tomato cultivation is around 21,981 ha with a production of 4,10,721 MT and a yield of about $18.68 \mathrm{Mt} / \mathrm{ha}$ (MOALD, 2017/18). Kathmandu and Bhaktapur are one of the most important tomatoes growing districts for meeting the growing demand of the Kathmandu Valley. The area and production under tomato in Kathmandu and Bhaktapur districts are 211 ha \& 20,453 $\mathrm{mt}$ and 176 ha and 4,569 MT, respectively (MOALD, 2017/18). Beside the importance as a commercial commodity, production of tomato is affected by several biotic and abiotic factors. Among them, incidence of insect pest and plant disease is considered as major factors with potential of significant losses in fruit yield. The devastating effects of major pests have played a crucial role for the determination of commercial value of the crops (Paneru and Aryal, 2004).

Using chemical pesticide is one of the common methods followed by the Nepalese farmer as it easily brings pest population below threshold level. Although use of chemical inputs like pesticides increases agricultural production it on the other side produces detrimental effects in human health and ecosystem (Aktar and Chowdhury, 2009).

Pesticide misuse and overuse causes harmful effects on non- target organisms and adds extra burden to the Nepalese society in terms of pesticide related health expenses, environmental pollution, crop losses due to resistance over the pesticide and sending extra costs both to farmers and the country as a whole (Thapa, 2003). Because of those situations, chemical pesticides are seen as a culprit for environmental mishaps. However, in Nepal, the use of active ingredients (a.i.) as compared to other countries on the per hectare basis is quite low (396 g/ha). However, lately overuse and misuse of pesticides has been observed in some of the crops like tomatoes (PPD, 2010)). Studies have shown that over $60 \%$ farmers using pesticides for over five years wait less than two weeks after spraying pesticides before harvesting the crop (Palikhe, 2002). Pesticides results in cancer, birth defects, reproductive problems, tumours, and damage of liver, kidney and neural organs. There exists a direct relationship between the extent of pesticides used and signs and symptoms of illness due to exposure among farmers (Kishi et al., 1995) In our country and other under developed and developing countries, the overuse of pesticides is linked up to the adverse effect on human and environment (Naidoo and London, 2010). Majority of pesticides users, being unaware of pesticide types, their mode of action, potential hazards and safety measures, waiting period to be followed. The sequential order of different groups of pesticides introduced in Nepal is: 1950s - organochlorines; 1960s - organophosphates; 1970s - carbamates; 1980s synthetic pyrethroids (Manandhar, 2007).

Nepal is blessed with a diverse agro-eco-zone, thus it has a marvelous opportunity for growing tomatoes seasonal as well as off-seasonal. Thus, farmers are encouraged to produce, and productivity of this crop has been increasing significantly for the last decade. Nepal has potential for fresh vegetable (tomato) and processed products in the international 
market as well. Reports suggested that use of pesticides in vegetables in Nepal is higher than other food products (Koirala and Dhakal, 2009). This study mainly helps us to know the major insects that reduce the yield of tomato. It will be useful to get information regarding the farmers' pest management strategy, knowledge on pesticide safety and also for knowing and understanding pesticide use practices among Kathmandu and Bhaktapur Districts.

\section{MATERIALS AND METHODS}

The study was performed in different municipalities of Kathmandu and Bhaktapur district. The study site of Kathmandu was Tarakeshwor, Kritipur and Budhanilkantha Municipality and the study site of Bhaktapur was Bhaktapur, Suryabinayak and Changunarayan Municipality. The total sampling size was 90 i.e. 45 respondents from Kathmandu and 45 respondents from Bhaktapur. The study focuses both on the large scale and small scale commercial cultivation of tomato crops on a randomized way to reduce the biasness. The pre-tested and semi structured interview schedule was used as a tool to collect data through household survey. Similarly, focus group discussion and key informant interview was conducted; secondary data was acquired from different sources.

A set of semi-structured questionnaires was prepared that focuses mainly on the demographic characteristics, cultivation status, pest management strategy and practice of pest management. The general information of the respondents regarding their gender, ethnicity, education status, main occupation, total landholdings were also included in the questionnaires.

The questionnaire survey was conducted from June 25, 2019, to September 28, 2019. The information obtained from the survey were analyzed using Microsoft Excel and the result was presented in the form of tables, pie charts and bar diagrams.

\section{RESULTS AND DISCUSSION}

\section{Socio-demographic status of the respondents}

Out of 90 respondents, $61.11 \%$ were male and the remaining $38.89 \%$ were female. The male were found to be high ( $82 \%$ ) in Bhaktapur and female respondents were found to be high $(60 \%)$ in Kathmandu. The most people actively working in the field were of aged group of $30-40$. Similarly the population of Janajati farmers was found actively working with $45.5 \%$ than other ethnic groups. Majority of the respondents had joined the primary level of education. Thus, this showed that most of the people were directly dependent on agriculture as their education status was low. Likewise, Out of the total farm surveyed, it was found that $80 \%$ of people had agriculture as their prime occupation followed by $9 \%$ had agriculture as secondary occupation, $7 \%$ of them were returnee migrants and about $4 \%$ revealed that they were involved in certain jobs/services. 


\section{Major insect pests and their occurrence}

The farmer had no adequate idea about the major insects infecting tomatoes in the surveyed area but following are the common insect pests attacking that area.

Table 1. Major insect pest of tomato in study

\begin{tabular}{lllc}
\hline Common Name & \multicolumn{1}{c}{ Local name } & Scientific Name & $\begin{array}{c}\text { Pest occurrence } \\
\text { (percent) }\end{array}$ \\
\hline $\begin{array}{l}\text { South American } \\
\text { Tomato Leaf Miner }\end{array}$ & Paat Khanne Kira & Tuta absoluta & $89 \%$ \\
Tomato Fruit Borer & Gabaroo & Helicoverpa armigera & $41 \%$ \\
Tobacco caterpillar & Surti ko paat khane kira & Spodoptera litura & $16.67 \%$ \\
Aphids & Lahi & Aphis gossypi & $39 \%$ \\
Whitefly & Seto Jhinga & Bemisia tabaci & $84 \%$ \\
\hline
\end{tabular}

Among all major insects, South American tomato leafminer was found to occurred with about $89 \%$ as a major pest then after Whitefly $(84 \%)$ which was followed by Helicoverpa armigera (41\%) and Spodoptera litura (39\%), respectively (Table 1). Pokharel, Rajbhandari and Shah (2017) also reported Tuta absoluta as the major infesting pest in these areas.

\section{Major problem faced for tomato production}

Among the 90 respondents surveyed, $32 \%$ of them had faced insect problems. Similarly, $26 \%$ of them had faced the problem of disease followed by $12 \%$ of unpredictable weather, $12 \%$ unavailability of inputs such as fertilizer, plastic, etc. and $18 \%$ irrigation because of shortage of water on that area, respectively.

\section{Pest management strategy}

Almost all the respondents had been adopting a chemical method for insect pest control except some IPM trained farmers. Generally, these IPM trained people had been using a chemical method as the last resort. Similarly, untrained respondents focused only on chemicals. Survey shows that $35 \%$ of the respondents with the majority used chemical methods along with some cultural methods, using trap crops, removal of infested leaves and fruits. While $26 \%$ of them use chemical method only, $22 \%$ of them use chemical + mechanical and $17 \%$ of them use biological method in combination with mechanical method as an organic practice (Table 2). 
Table 2. General pest management practices

\begin{tabular}{lcc}
\hline \multicolumn{1}{c}{ Management Practices } & Frequency $(\mathbf{n = 9 0})$ & Percentage (\%) \\
\hline Biological + Mechanical & 15.00 & 17.00 \\
Chemical + Mechanical & 20.00 & 22.00 \\
Chemical + Cultural & 32.00 & 35.00 \\
Chemical only & 23.00 & 26.00 \\
\hline Total & $\mathbf{9 0 . 0 0}$ & $\mathbf{1 0 0 . 0 0 \%}$ \\
\hline
\end{tabular}

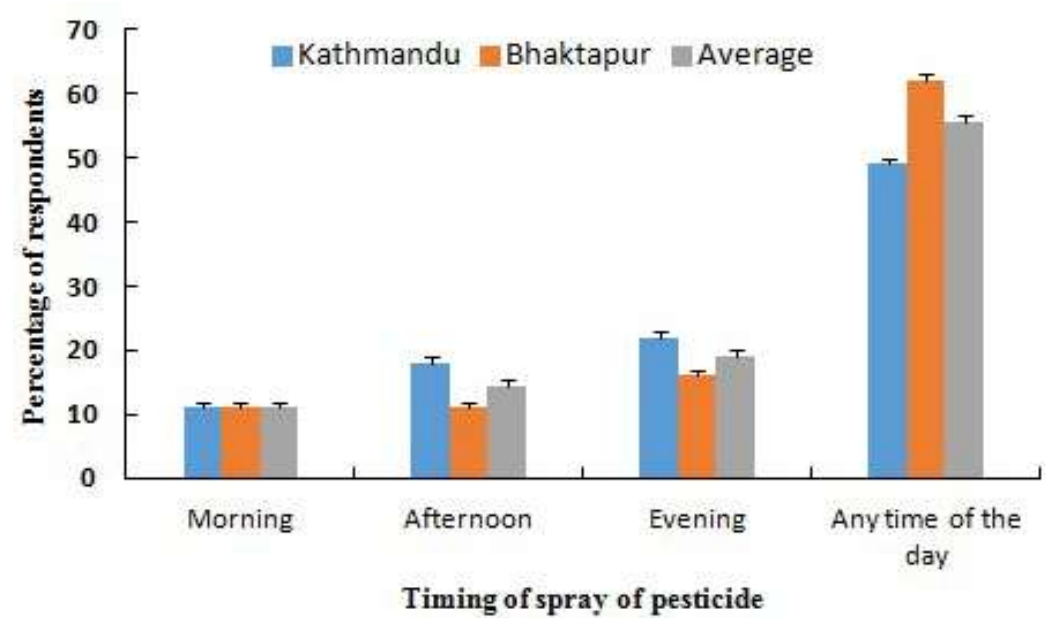

Fig. 1: Farmers' practice on pesticide application

\section{Pesticide use}

\section{Application time}

Pesticides application time was one of the major factors for the safety of the applicators during pesticide sprays. Survey data revealed that the majority $(55.5 \%)$ of people sprayed pesticide at any time of the day, $19 \%$ sprayed the pesticides in the evening, $14.5 \%$ of them sprayed in the afternoon while $11 \%$ of the respondents sprayed the pesticides in the morning. The results showed that farmers were unaware about the timing of spray of pesticide (Fig. 1).

\section{Decision of Spray}

The study found that the majority of the respondents about $42 \%$ sprayed pesticides before pest emergence, whereas $31.5 \%$ of the respondents sprayed pesticides after the damage was seen. Similarly, $26.5 \%$ of the farmers responded that they used pesticides after pest 
emergence (Fig. 2). This showed that most of the farmers were spraying unnecessarily in the field.

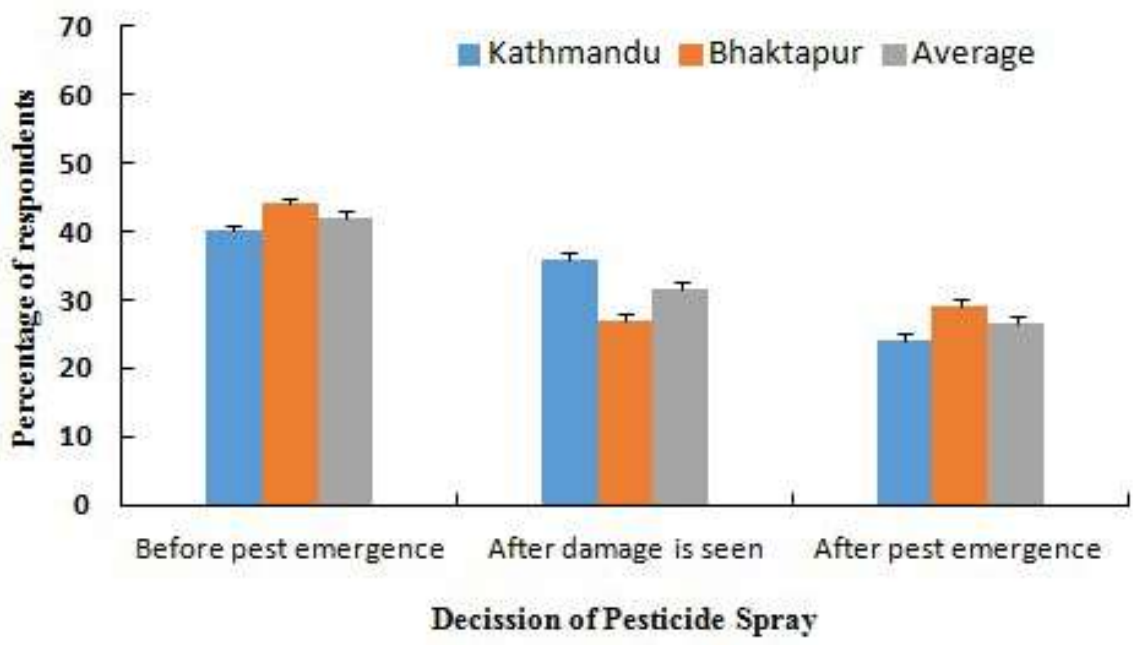

Fig. 2: Distribution by the decision of chemical pesticide spray

\section{Frequency of application}

Survey revealed that the majority (54\%) of the farmers spray pesticide 1-4 times per season, $28 \%$ farmers spraying 4-8 times per season and $18 \%$ of the respondents were found spraying more than 8 times per season (Fig. 3). This revealed that farmers were spraying pesticides haphazardly on the field.

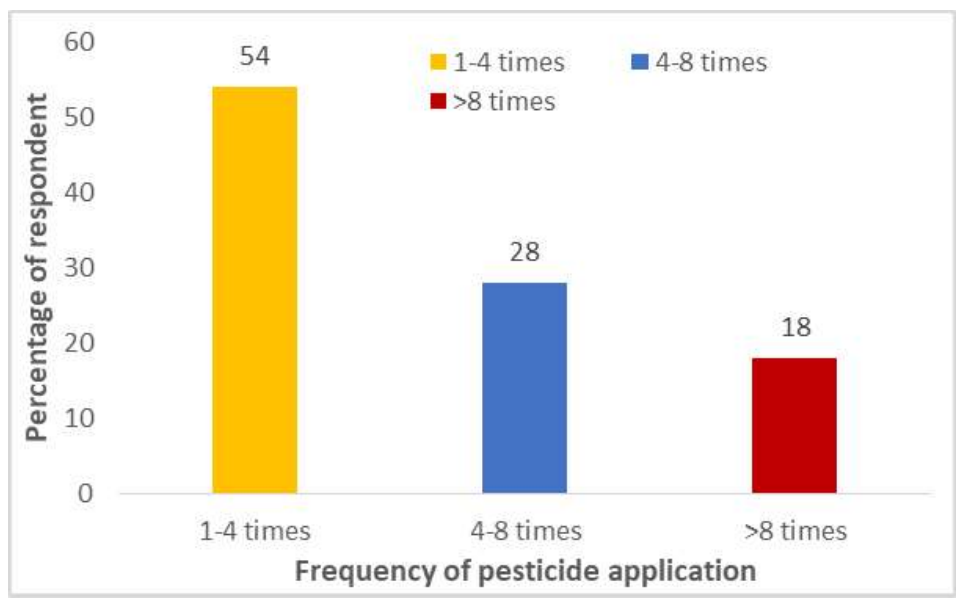

Fig.3: Frequency of pesticide application 


\section{Dose of pesticide use}

Most of the respondents, $70 \%$ were found to depend on agro-vet for the recommendation of pesticides. $13 \%$ of the respondents said that they used $1-3 \mathrm{ml}$ of pesticides whereas $10 \%$ responded that they had used 3-6 $\mathrm{ml}$ of pesticides, $7 \%$ responded that they used dose of greater than $6 \mathrm{ml}$ of pesticides irrespective of pesticide type (Fig. 4). These doses are dependent to the type of pesticides recommended by the Agro-vet. The results showed that farmers were not practicing spraying pesticide in required doses risking the plant's health along with their own health.

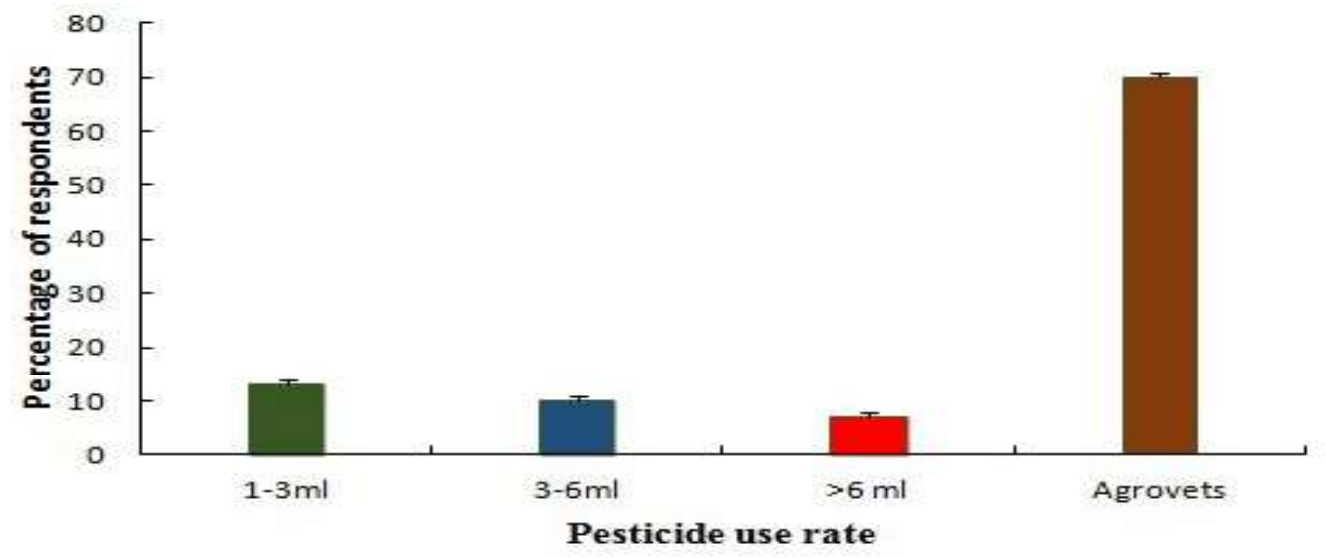

Fig. 4: Distribution by pesticide use rate per season

\section{Personal safety measures practiced by farmers during mixing and application of pesticides}

The survey data revealed that $45 \%$ of farmers had used masks only as protective equipment while spraying pesticides. The ordinary mask and plain towel if farmers used to cover their face were considered also as a mask in this regard. Similarly, $24 \%$ of the farmers were found to have been using masks along with apron while spraying pesticides. Only $20 \%$ of the farmers are found to have been using a combination of protective equipment which included masks, apron, boot, goggles and other equipment (Fig. 5). Likewise, 11\% of the farmers were ignorant about safety and had not been using any equipment while spraying pesticides. Thus, farmers were almost ignorant about the entry of pesticides in the body by various means other than oral route and cause expose to toxic pesticides which leads to various health related problems. 


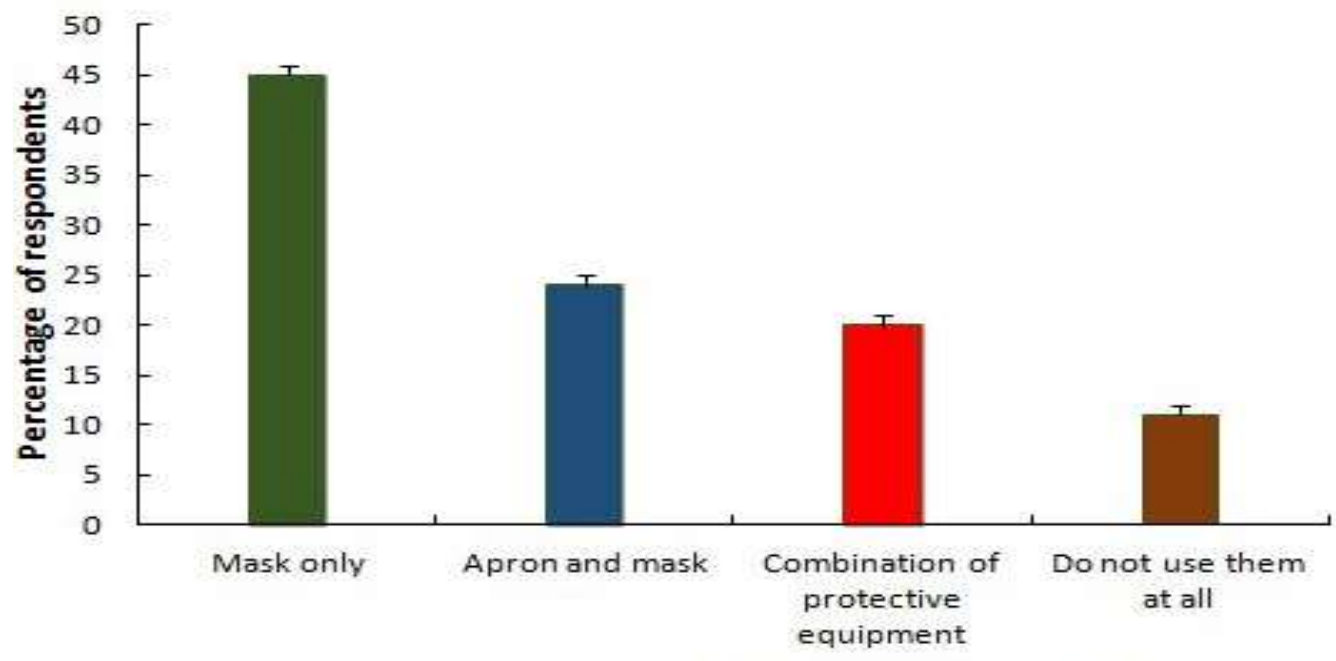

Personal Safety measures practiced

Fig. 5: Cumulative percentage of personal safety measures practiced by farmers

\section{Storage of pesticide}

Survey revealed that $11.11 \%$ of the respondents had been using close rack for the storage of pesticide, $5.56 \%$ had been using bedroom, $24.4 \%$ of respondents had been using storeroom, $5.56 \%$ had been using kitchen, $43.37 \%$ of respondents practiced outside of their house, $10 \%$ of the farmers had been using other places like field or cattle shed for the storage of pesticides This demonstrates the farmer's lack of knowledge of pesticides and the appropriate approach for storing pesticides. Storing those pesticide in living areas can increase the potential for higher exposure, especially when these places are the place where farmers eat, prepare food and sleep. (Matthews, 2008) also reported that $27 \%$ of 8500 smallholder farmers in 26 countries stored pesticides in the home or in open areas, and nearly half indicated that they rarely or never locked pesticides away.

\section{Status of unused date expired pesticides}

Majority of farmers (46\%) were found burying, $13 \%$ of farmers were found disposing them in the garbage, $13 \%$ of them were found throwing it near water channels, $12 \%$ of them were found throwing the date expired pesticides in the open places and about $16 \%$ of them were found burning the unwanted and date expired pesticides. These practices may lead to environmental contamination and risk to human health, and have been reported as a major problems in the study of Matthews in 2008. 


\section{Response on label and instruction of pesticides}

The study found that $25.56 \%$ of the respondents studied instruction on the labels of pesticides they brought, $33.33 \%$ of the respondents did not read the labels of pesticides and $41.11 \%$ of the respondents were totally unaware of the labels of pesticides. This shows that almost half of the respondents were unaware of the label and instructions of pesticides that might cause improper selection of pesticides, wrong dose, mishandling in applying pesticides and not waiting in accordance with the given waiting period after applying pesticides.

\section{CONCLUSION}

The study was conducted to know the major insect pest and pesticide application practices adopted by the farmers of Kathmandu and Bhaktapur districts. The study showed that among many insect pests attacking different parts of tomato, South American tomato leafminer were found to cause high economic loss. Farmers were found considering the pesticides as the major solution to protect their crops from pests. Majority of the farmers were found not being able to use pesticide at the right dose, right time and were found to have been spraying haphazardly. Farmers were ignorant about using protective equipment while spraying pesticides. Farmer's attitude, knowledge and practice on pesticide were found not sufficient to manage the risk of pesticide hazards. Due to this, not only pesticide applicators but also consumers' health is affected by the pesticides. Environment is also affected and polluted by pesticides. Government policy and programs need to focus on solving these problems and corrective actions need to be planned to reduce the pesticide risk.

\section{ACKNOWLEDGEMENTS}

A special acknowledgement and appreciation goes to all respondents, farmers and community people of the study area who generously provided kind assistance and helped with valuable information and time during the field survey study.

\section{LITERATURE CITED}

ABPSD. 2016. Statistical information on Nepalese Agriculture. Agribusiness Promotion and Statistic Division, Singha Durbar, Kathmandu, Nepal.

Aktar, M.W. and A. Chowdhury, 2009. Impact of pesticides use in agriculture: their benefits and hazards. Interdiscip Toxicol. 1-12.

Joshi, D., B.P. Rajbhandari and L. Sah, 2017. Management practices adopted by commercial tomato growers against Tuta absoluta. Nepalese J. of Agricultural Sciences.15 
Kishi, M., N. Hirschhorn, M.S, Djajadisastra and D. Strowman, 1995. Relationship of pesticide spraying to signs and symptoms in Indonesian farmers. 21:124-133.

Koirala, P., S. Dhakal and A. Tamrakar 2009. Pesticides and food safety issues in Nepal. The J. Agric. Environ.10:128-132. Retrived from https://doi.org/10.3126/aej.v10i0.2137.

Manandhar, D. 2007. Pesticides in Nepal. Kathmandu: SD Manandhar Publisher.

Matthews, G. 2008. Attitudes and behaviors regarding use of crop protection products- A survey of more than 8500 smallholders in 26 countries. Crop Prot. 27:834-846.

MOALD. 2017. Statistical information on Nepalese Agriculture. Ministry of Agriculture and Livestock Development, Singh Durbar, Nepal.

MOALD. 2017/18. Statistical information on Nepalese information 2073/74 BS. Ministry of Agriculture and Livestock Development, Agribusiness promotion and Statistics Division, Kathmandu, Nepal. DOI: https://doi.org/10.3126/janr.v3i1.27181

Naidoo, S. and L.R. London, 2010. Pesticide safety training and practices in women working in small-scale agriculture in South Africa. J. Occupational Environ. Med. 67(12): 823-828.

Palikhe, B. 2002. Challenges and options of pesticide use in the context of Nepal. Plant Protection Directorate, Hariharbhawan, Lalitpur.

Paneru, R.B. and S. Aryal. 2004. Evaluation of biopesticides against tomato fruit worm (Helicoverpa armigera Hubner) on tomato at Khumaltar. Advances of Horticulture Research in Nepal. 391-395.

PPD. 2010. Annual progress report. Hariharbhawan, Plant Protection Directorate, Lalitpur.

PRMD. 2016a. Pesticide Statistics (in Nepali). Pesticide Registration and Management Division, Ministry of Agricultural Development, Kathmandu, Nepal.

PRMD. 2016b. Pesticide:Awareness publication (in Nepali). Pesticide Registration and Management Division, Ministry of Agricultural Development, Kathmandu, Nepal.

PRMD. 2018. Pesticide Statistics (in Nepali). Pesticide Registration and Management Division, Ministry of Agricultural Development, Kathmandu, Nepal.

Thapa, R. 2003. Pesticide pollution and integrated pest management. In: F.P. Neupane(ed), Integrated Pest Management in Nepal: Proceedings of a National Seminar, Kathmandu, Nepal, September 25-26, 2002. Himalayan Resource Institute, New Baneshwor, Kathmandu, Nepal. pp.175-194.

Vainio, H 1999. Fruits, vegetables and pesticides- do we know what we are eating? Scandinavian J. of Work Environ. and Health. 25:161-162. 